\title{
On Becoming A Psychiatrist: A Resident's Perspective
}

Phebe M. Tucker, M.D.

Oklahoma Teaching Hospitals, Oklahoma City, Oklahoma

Follow this and additional works at: https://jdc.jefferson.edu/jeffjpsychiatry

Part of the Psychiatry Commons

Let us know how access to this document benefits you

\section{Recommended Citation}

Tucker, M.D., Phebe M. (1989) "On Becoming A Psychiatrist: A Resident's Perspective," Jefferson Journal of Psychiatry. Vol. 7 : Iss. 2 , Article 10.

DOI: https://doi.org/10.29046/JJP.007.2.008

Available at: https://jdc.jefferson.edu/jeffjpsychiatry/vol7/iss2/10

This Article is brought to you for free and open access by the Jefferson Digital Commons. The Jefferson Digital Commons is a service of Thomas Jefferson University's Center for Teaching and Learning (CTL). The Commons is a showcase for Jefferson books and journals, peer-reviewed scholarly publications, unique historical collections from the University archives, and teaching tools. The Jefferson Digital Commons allows researchers and interested readers anywhere in the world to learn about and keep up to date with Jefferson scholarship. This article has been accepted for inclusion in Jefferson Journal of Psychiatry by an authorized administrator of the Jefferson Digital Commons. For more information, please contact: JeffersonDigitalCommons@jefferson.edu. 


\title{
On Becoming a Psychiatrist: A Resident's Perspective
}

\author{
Phebe M. Tucker, M.D.
}

\section{INTRODUCTION}

Developing an identity as a psychiatrist is a process which has been seen by many to span an individual's career; from the first decision of choice of a career, through residency training and beyond, into the years of practice. As part of a “'Residents' Day Paper,'” psychiatrists in the Oklahoma City area were surveyed in order to look at their perceptions of the growth of their professional identities. Despite the limitations of a small sample population, limited to one metropolitan area, some interesting common patterns emerged: the psychiatrists surveyed had diverse educational and cultural backgrounds, similar practical and unconscious motivations for entering the field, influential role models, and specific developmental tasks mastered during and after training.

\section{METHODS}

Fifty questionnaires were put in university mailboxes or mailed to office addresses, with a cover letter explaining simply that the survey was for a “'Residents' Day Paper." Candid, anonymous responses were requested. Questions asked respondents to specify their level of experience in psychiatry, their undergraduate majors, and any former occupations. They were asked to indicate when they decided on psychiatry as a career, and why they chose this specialty. In addition, they were to discuss reactions of family or friends to their career choice, satisfying aspects of their career as well as drawbacks, and whether they would specialize in psychiatry if they could choose again. They were asked to name any supervisors in psychiatry who strongly influenced them, and whether they had any mentors. Finally, they identified the most difficult tasks mastered during different years of training and later in practice.

\section{RESULTS}

Response rate was $76 \%(\mathrm{~N}=37)$. Respondents ranged in years of experience from less than one to forty, as shown in Figure 1. Results were difficult to tabulate statistically, as questions were unstructured and responses were subjective and creative. However, key responses that occurred repeatedly were analyzed with simple statistics, and were highly significant. Many responses were 


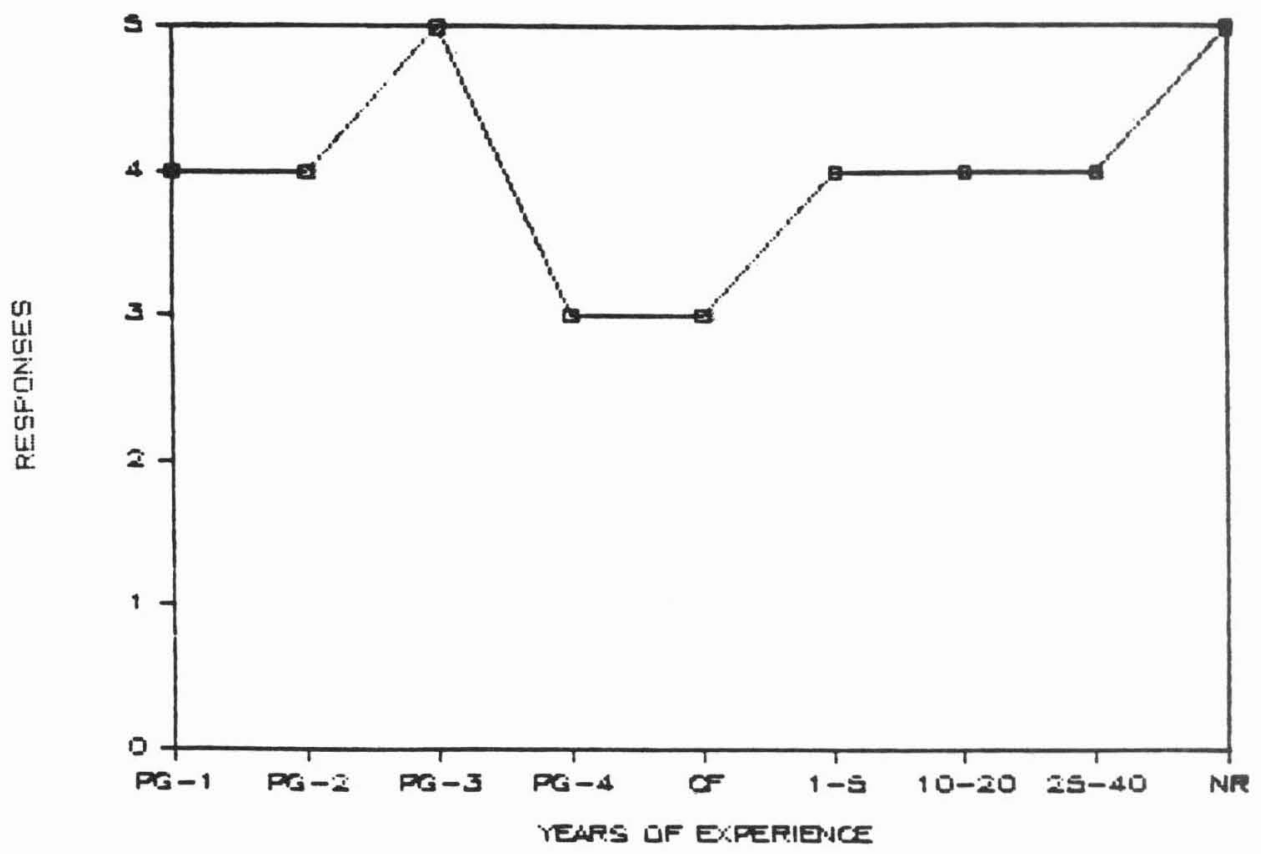

FIGURE 1. Psychiatrists' years of experience

qualitatively consistent with several nationwide surveys, and will be discussed individually.

Psychiatrists who responded, appeared to examine themselves and the attitudes of society toward them candidly, and critically. Despite their critiques, $100 \%$ of those who responded, regardless of their level of training, were satisfied with their choice of psychiatry and would choose it again. Most had chosen psychiatry in medical school $(19 / 37)$, often because of personal contact with a psychiatrist who served as role model. However, several $(12 / 37)$ "received the calling" after practicing in other medical specialties; they felt the emotional needs of their patients were being neglected in these fields. Some (3) had decided as undergraduates, one before college, and two gradually over time. Their reasons for choosing psychiatry are important, and will be discussed.

What stood out in this survey of psychiatrists was their diversity-in education, careers, cultural backgrounds, and life experiences. Respondents had a wide variety of undergraduate majors. In Figure 2, respondents' majors are compared with those of an equal number of randomly chosen medical graduates from the class of 1985 at the University of Oklahoma. The random medical graduates cluster in the "hard-core" science courses, especially chemistry, biology, and zoology; the psychiatrists' majors were generally more spread out, with more majors in psychology, general science, and literature. It is well known that many of the pioneers in psychiatry also had diverse educational back- 


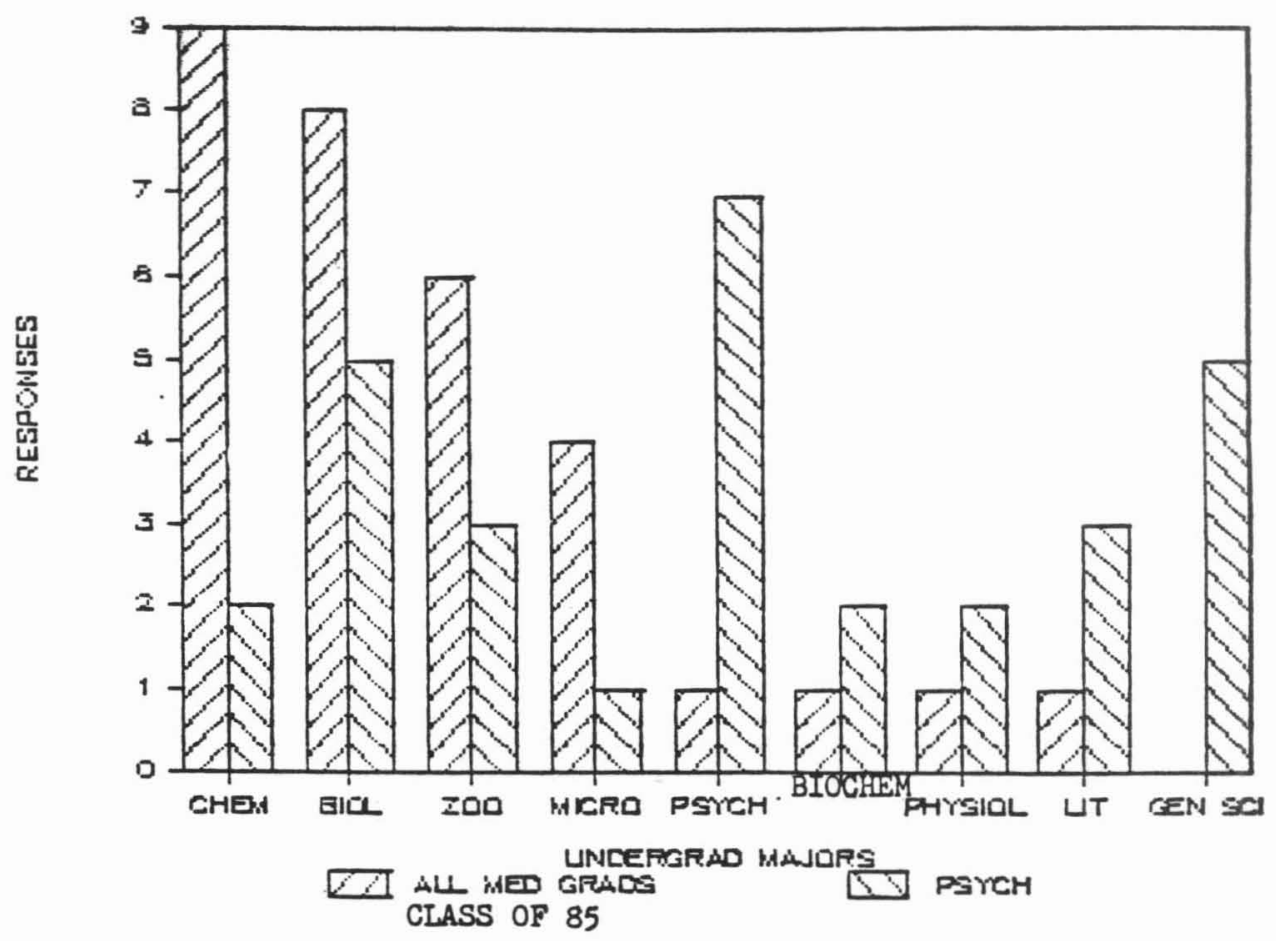

FIGURE 2. Undergrad majors

grounds. This is fitting, as psychiatry requires a breadth and flexibility in conceptualizing human behavior and emotions.

In addition, respondents showed a breadth of experience before entering the field. Many had worked at demanding careers, had been in military service in wartime (5), had been chemists, worked in electronics, served as officers in public housing, were teachers, physicians in other specialties, and even a taxicab driver. Many were parents.

Several respondents had adjusted to new cultures and learned new languages. (Ten were foreign medical graduates.) Many authors have noted that bi-cultural or minority individuals are highly represented in psychiatry. In thinking about this, it may be that an individual who is separate from the majority social, religious, or political beliefs may find in psychiatry, a humanbased ideology that transcends the superficial differences. In his own adaptation to a different culture, he experiences a stripping away of superficial layers to the core of his being, then reconstruction. This is essentially the same experience he will guide his patients through in therapy. Theoretically he will be more flexible and tolerant. And lastly, residents entering training have a breadth of experi- 
ence in their medical work, for as students or physicians they have already dealt with life and death situations in helping their patients and their families.

Looking more deeply at motivating factors, to many respondents, human relations and emotions were highly valued, and a primary reason for choosing psychiatry as a career. Eight identified an interest in psychological problems. Seven had a desire to understand people and human behavior, or "what makes people tick." Five reported a sheer enjoyment in working with people. A desire to help others and improve their quality of life was important to eight. Combining these several related areas as the "human element" and applying a chisquared test, "human element" as a motivation differs from random distribution at a significance of less than .001; obviously human factors were important to these psychiatrists. Influential role models and good psychiatry rotations played a role for seven. Three saw that they had a natural ability in the field. Seven were stimulated intellectually, one seeing psychiatry as a "terra incognita" requiring a pioneer spirit; two liked psychiatry's blending of the humanities and natural sciences. Less altruistic factors were; availability of jobs in psychiatry (8), and the single most often identified reason, a good lifestyle that allowed time and energy for family life and other interests (17). This may be seen as essential for a psychiatrist, to be consistent in his own life with his teachings. By seeing to his own emotional needs and his responsibilities to family and friends, he may be better able to encourage his patients (by his own example) to see to their needs and to broaden their emotional life. Freud wrote that a goal of therapy was to help our patients to both work and love.

Looking a layer deeper, unconscious factors were touched on by a few; or perhaps more accurately, once unconscious factors that had become conscious. Two recognized that they entered psychiatry in part to overcome their own doubts and to solve their own problems. Three wanted to better understand themselves and to grow. One felt that he had been programmed into the caretaker role unconsciously, and another felt that a fear of death steered him to psychiatry. Unconscious motivations of psychiatrists in their career choice have been the subject of much speculation and some research. Vaillant and Menninger wrote that physicians in general, attempt to master childhood experiences of illness, or unhappiness in the family by caring for others (1); at least one study has supported this. Searles, Burton and others have pointed out the possibility that therapists use therapy to heal themselves by giving to others what they wish to have received, or by identifying their own dependency needs in their patients (2). Many studies have looked at therapists' family of origin, with the logic that the family is the transmitter of values and beliefs, as well as the source of crucial early relationships and emotional experiences. A Canadian study in 1987 reported that surveyed psychiatrists (compared with other physicians) perceived their fathers as more anxious, less admirable and their mothers as less consistent, less admirable, and somewhat more intrusive (3). In looking at sibling relationships, a large study of psychiatrists found that $56 \%$ considered 
themselves to be the dominant sibling (4); this could be the origin of nurturant behaviors that persists in their careers. In looking at emotional traits, two studies noted a high level of manifest anxiety among analytic trainees (5); however, it is difficult to determine if this anxiety predated training or was a result of it. These are just a few of many such studies and it is clear that there is no consensus. In fact, it would be difficult to demonstrate that unconscious factors are more important to psychiatrists than any other caretakers. Psychiatrists rather, may be more apt to articulate their unconscious motivation due to their dynamic training or personal psychotherapy. This remains difficult to measure.

Further as a logical point of departure; respondents were characterized by a strong interest in the human. They themselves possess personality traits that we think of as more human and compassionate. The survey did not ask respondents to comment on their own positive attributes; rather, we may look to the literature. Karl Menninger explored some of the positive personality traits he and others felt were important to psychiatrists. He sees human qualities as most important. "The psychiatrist must be, in the platonic sense, a good man . . The psychiatrist as a person is more important than the psychiatrist as a technician or scientist . . because of the intimate relationship between patient and psychiatrist" (6). He surveyed most of the large psychiatric training centers in the country in the 1950's to look at the human qualities sought out in prospective residents. Integrity, warmth, capacity for growth and development, and maturity were valued. Interpersonal assets were tolerance, empathy, desire to relieve suffering, and likeability. Training centers looked for a blend of cognitive abilities: intelligence, verbal facility, common sense, intuitiveness, and imagination. That is indeed a tall order! Human traits are still highly valued despite the recent emphasis on the biological; an April 1988 survey of psychiatrists found increased emphasis on compassion, interest, and tact compared to a 1980 survey (7).

Once respondents had chosen psychiatry due to a complex interaction of interests, education, experiences, and personality, they announced their choice. This drew mixed reactions from family and friends. These reactions were described openly with some irony and amusement, and they did not negatively affect their career satisfaction ( $100 \%$ satisfaction). Several remembered negative attitudes that reflect the stigma attached by some to the field. Thirteen had totally negative reactions. For four it was, "Why did you waste four years studying medicine if you were going to leave the profession?" Or for six: "You could be anything. Don't you want to be a real doctor?"' Other responses were: "'quietly horrified," skeptical, griefstricken, and "underwhelmed." Another had a blunt response from family friends: "You're crazy!" Sixteen had neutral or mixed reactions, or amusement. Six reported all positive, supportive reactions. Two of these were qualified by relatives adding, "Good, now you can start treating me!'”

Finally, in assessing their career choices, respondents saw fewer drawbacks than attractions. Those who did discuss drawbacks touched most often on 
psychiatry's image. Six were unhappy with prejudice from other medical specialties. Five disliked fear, ignorance, and prejudice from society toward the mentally ill. Four felt psychiatry was not as well rewarded financially. Two saw the effects of "sharing the pain of others daily" and "not taking it home" as difficult. Three regretted being out of the mainstream of medicine. Two found the sense of theoretical uncertainty and "lack of objective yardsticks" a drawback; they felt that progress is often slow and hard to measure.

Once he has chosen his specialty and begun training, the psychiatrist in training passes through certain predictable developmental stages in building his identity. This became clear in the survey as respondents were asked to identify the tasks most difficult to master during the four years of residency and beyond. One of the tasks most often seen as problematic in the intern year was developing an identity as a physician (10); applying a chi-squared test, this is significant at $\mathrm{p}<.01$. During the medical rotations, the psychiatry intern represents a specialty sometimes seen as nonscientific (or "hocus-pocus" as one put it) by his medical peers, and this may affect his confidence. He is faced for the first time with responsibility for care of seriously ill patients; he often makes decisions in life or death situations, and will lose many of his patients. Ten in the survey found the workload, especially in VA medicine, to be the most difficult hurdle. They described sleep deprivation, social deprivation and inadequate support emotionally and educationally. This, of course, would be true for any intern and there are several studies supporting this. A 1986 survey of 215 interns found 14\% to be "psychiatric cases" with symptoms serious enough to warrant treatment; another $11 \%$ admitted to use of alcohol and minor tranquilizers to cope (8). Another study of a large medical intern class found almost one-third of interns reporting symptoms of major depression during the year. Of this group onethird (incredibly enough) had suicidal ideations at one point (9). Somehow, most get through this time.

As the intern begins his inpatient psychiatric rotation, he is immediately faced with a new set of tasks. He becomes a psychiatrist overnight; several saw that self confidence was a problem here. One particular source of strain identified in the survey involved serving as a member of a ward multidisciplinary team, which as one resident put it "means the resident takes all the responsibility for the patients but is forced to share decision-making with nonmedical personnel." Ironically, along with the most responsibility he often has the least clinical experience. And finally, three identified interstaff conflicts in which being invited to participate caused discomfort. As one resident put it, "It was difficult to deflect staff pressures." With more experience, some flexibility, good supervision, and as some training programs have, a Residents' Support Group, the resident will grow from these interpersonal stressors so that he can better tolerate uncertainty.

In the second and third years of residency, respondents identified the main task as developing a firmer identity as a psychiatrist. Five named this directly, 
and another five noted that learning to be a therapist was most difficult. Several others named more specific aspects of psychotherapy as their main task; avoiding identifying with patients, separating their own feelings from their patients (2), and gaining a better understanding of themselves (2). It is no surprise that learning psychotherapy is seen as difficult, for it requires entirely new skills and sensitivities. The resident learns to "listen with the third ear" as Reik puts it, balance empathy and objectivity, and recognize the patient's defenses and his own defenses and blind spots. Three respondents described "feeling like nothing is certain" at times. Three said they just did not know what to do next with their longterm patients. In addition to learning about psychotherapy and dynamics, big strides are made in pharmacology, ward management, consultationliaison, family and marital therapies, and cognitive behavioral therapies. Because of the overwhelming amount of theory and technique to master, some authors describe the resident embarking on a "quest for omnipotence" at this stage (10). While only one respondent identified this quest; several did describe feeling as if they were "spinning their wheels."

One way in which most of the respondents coped with "spinning their wheels" was to emulate a mature role model, the mentor. Actually, thirteen said they had many mentors, a kind of "mentor mosaic" as one put it. Several members of the teaching staff at the University of Oklahoma were named as mentors, as well as a few practitioners in the community. In addition, Ramana, West, Menninger, Manfred Bleuler, Hargrove and others were remembered. Some of the qualities that were admired were personal strength, psychotherapeutic skills, compassion, enthusiasm, and breadth of knowledge. As one respondent said, "I've always sought out the sages and tried to both projectively identify and de-differentiate!' Supervision was named by several as the avenue by which the mentor helps the resident grow. In that it is an affectively charged helping interchange, it parallels therapy. Two described experiencing "wounded narcissism" in supervision and one said "learning therapy is hard on the ego." If the resident does not choose to have personal psychotherapy, supervision can help the resident experience first hand the power of the unconscious (his own), as well as to consolidate his skills.

The fourth year of residency was accompanied by "separation anxiety" as the resident prepares to enter practice (5). One described the "fear of being out on my own" and three worried about consolidating skills. In comparing this with the literature, a nationwide survey of newly graduating residents supports this: $73 \%$ experienced moderate to incapacitating anxiety, and 58\% feelings of depression (11). The central question is "What kind of psychiatrist will I be?" A sense of identity diffusion described by Hales and Borus was also apparent in this survey as respondents described diverse worries-reading enough, setting limits, public speaking, and adapting to child psychiatry (3). The mentor at this stage may have a new value to the resident; by acknowledging his own necessary 
narrowing of focus in his career, he helps the resident realize he can't be expert in all areas.

After residency, professional identity continues to grow. During the first three years after training, issues became more diverse as practitioners took different career paths. Two still felt that preserving their identity as a psychiatrist was hard, and two had difficulty in the transition to attending status. For one, the fear of succeeding financially and professionally was a problem. Others included using what was learned in residency, politics, finding time for family and career, and paying school debts. The later years still presented the need to hold on to the identity as psychiatrist as important to two respondents. In addition, keeping up with new advances, dealing directly with money as a treatment issue, dealing with the poor image of psychiatrists, planning for retirement, and getting services for the indigent were mentioned. A recent Oklahoma Psychiatric Association meeting voiced some of the same concern as the respondents: that the economic climate of the future may also shape our image. HMO's and third party payors will limit our treatment, and competition from non-psychiatric therapists may lead many psychiatrists to emphasize medical therapies.

In summary, psychiatrists surveyed in this study were characterized by diversity in cultural background, former careers, and education. They indicated strong preferences for human contact, but were also motivated in their career choice by influential role models, intellectual challenge, widespread opportunities in the field, lifestyle considerations, and for several unconscious factors. During training, they progressed from developing an identity as a physician to developing an identity as a psychiatrist. This latter process was seen to continue throughout their careers, and was affected by the attitudes of society and other physicians toward psychiatry, as well as by the changing economic climate in medicine.

This study might be enhanced by surveying other groups as controls; nonpsychiatric physicians or nonmedical therapists. Such a comparison might help determine whether the psychiatrist's development is unique among his closely related colleagues, or whether it is parallel.

\section{REFERENCES}

1. Frank Hallie, Paris Joel: Psychological factors in the choice of psychiatry as a career. Canadian Journal of Psychiatry 32:118-122, March 1987

2. Ibid

3. Ibid

4. Bossard J, Boll E: The large family system, 1956, quoted in Henry, William E, Sims, John S, and Spray SL, Public and Private Lives of Psychotherapists. Jossey-Bass Publishers, 1973

5. Hales RE, Borus JF: A reexamination of the psychiatric resident's experience in the general hospital. General Hospital Psychiatry Nov 8(6):273-8, 1986 
6. Menninger Karl: What are the goals of psychiatric education? Bulletin of Menninger Clinic, quoted in Holt, Robert R., Op. Cit., 259, 1952

7. Langsley Doland G, Yager Joel: The definition of a psychiatrist: Eight years later. The American Journal of Psychiatry 145:469-475, April 4, 1988

8. Hurwitz TA, et al: Impaired interns and residents. Canadian Journal of Psychiatry 32(3):165-169, April 1987

9. Ibid

10. Sharaf Myron R, Levinson Daniel: The quest for omnipotence in professional training: The case of the psychiatric resident. International Journal of Psychoanalysis, reprinted from Psychiatry: Journal for the Study of Interpersonal Processes, Vol, 27, No. 2, May 1964

11. Hales RE: Op. Cit. 